\title{
A stable home: Autocorrelated Kernel Density Estimated home ranges of the critically endangered Elongated Tortoise
}

\section{Authors}

Ysabella Montano ${ }^{1}$, Benjamin Michael Marshall ${ }^{1}$, Matt Ward ${ }^{1}$, Ines Silva ${ }^{2,3}$, Taksin Artchawakom ${ }^{4}$, Surachit Waengsothorn ${ }^{5}$, Colin Thomas Strine ${ }^{1 *}$

\author{
Affiliations \\ ${ }^{1}$ Suranaree University of Technology, Nakhon Ratchasima, Thailand \\ 2 (CASUS), Center for Advanced Systems Understanding, Görlitz, Germany \\ ${ }^{3}$ (HZDR), Helmholtz-Zentrum Dresden-Rossendorf, Dresden, Germany \\ ${ }^{4}$ Population and Community Development Association, Bangkok, Thailand \\ ${ }^{5}$ Sakaerat Environmental Research Station, Nakhon Ratchasima, Thailand
}

\section{Corresponding author email}

*strine.conservation@gmail.com

\begin{abstract}
Home range analysis is a standard and fundamental concept in ecology used to describe animal space use over their lifetimes. Connecting home range sizes with animal characteristics, location, and habitat can be used to inform conservation decisions. Reptiles are frequently lacking robust estimates of space use, particularly reptiles in tropical regions. Here we analyse a publicly available dataset, collected by the authors of this study, describing the movements of Critically Endangered Elongated Tortoises (Indotestudo elongata). The tortoise data included the locations of 17 tortoises (12 females, 5 males) collected on average once every three days for an average duration of $353.76 \mathrm{SE} \pm 33.10$ days. We use these data to estimate the home range of Elongated Tortoise, and explore how tortoise size and sex influences home range size. To mitigate issues resulting from low effective sample sizes and low temporal resolution of the data, we used a modern home range estimation method Autocorrelated Kernel Density Estimators (AKDE). We found 14 of 17 individuals appear to be occupying a stable home range (using variograms to determine range residency). The average AKDE home range for all 14 individuals with range residency was $44.81 \pm 10.44$ ha. Bayesian Regression Models suggest comparable size estimates between male and female home ranges, despite males being physically larger than females in both mass and carapace length. These AKDE home range estimates have the added utility of being more comparable with other studies, less susceptible to errors from a suboptimal tracking regime, and are well positioned for inclusion in future metaanalyses.
\end{abstract}

\section{Keywords}

testudine, autocorrelated kernel density estimator, spatial ecology, space use, Thailand, Indotestudo elongata 


\section{Introduction}

Understanding an animal's lifetime space use can yield insight into many aspects of its ecology. Most importantly we can identify the spatial requirements for maintaining healthy populations (Di Franco et al., 2018). We can better optimise our limited conservation resources by using methods that quantify animal space use - which is often explored via expensive and long-term datasets - in a more efficient manner (Laver \& Kelly, 2008). The most commonly used metric for quantifying an animal's lifetime space use is termed home range (Burt, 1943; Worton, 1989; Fauvelle, Diepstraten \& Jessen, 2017). Here we follow Silva et al. (2021) and define home ranges as the lifetime space use of an animal.

Information on home range sizes and location can begin to elucidate the decision-making processes animals engage in. Decisions based upon resources (Mitchell \& Powell, 2004, 2012; Powell \& Mitchell, 2012), topography, and habitat can all filter down to impact animal space use (Fieberg \& Kochanny, 2005), and aids in understanding an animal's spatial niche (Xirouchakis et al., 2021). Understanding these phenomena in target species can have implications for both land-use and protected area management (Linnell et al., 2001; Viggers \& Hearn, 2005; Houser, Somers \& Boast, 2009). For example, Breininger and colleagues (2011) calculated home ranges for Indigo snakes (Drymarchon couperi) and concluded that the species needed large land tracts with substantial corridors between sites to avoid significant sources of road mortality. However, these tools only have value if the underlying data are treated properly, and the output is interpreted in a biological context.

Traditional approaches for estimating home ranges such as Minimum Convex Polygons (MCP), which essentially draw a polygon around the outermost collected points from a spatial dataset, are still widely used in herpetological research despite serious drawbacks (Crane et al., 2021). Specifically, MCPs tend to mis-estimate true space use (Silva et al., 2020) potentially leading to false conclusions when modelling predictors of home range size (Crane et al., 2021). The MCP approach is often inappropriate for comparisons among studies because it is sensitive to the tracking regime, tracking duration, and location error; and thus may yield flawed comparisons (Silva et al., 2020). If data are autocorrelated, Traditional Kernel Density Estimators (KDE) generate outputs which are not comparable between studies because KDEs are highly sensitive to changes in the duration and intensity of data collection, as well as kernel parameterisation (Averill-Murray, Fleming \& Riedle, 2020; Silva et al., 2020). In a simulation study, Silva et al (2020) found that consecutive datapoints needed to be spaced multiple months apart in order to satisfy the assumption of independence required for traditional methods (e.g., KDEs). Substantial thought should therefore be put into the choice of home range estimator and the methodological approach before quantifying and comparing home range outputs (Signer \& Fieberg, 2021). It is also critical to tie the biology of the target study species to the intended estimators and assess whether the tool is applicable given the nature of the animal's movement processes, the techniques used to collect the data, and the research question asked. Avoiding misestimation is particularly important given that spatial ecology research may inform conversation strategies (Fraser et al., 2018).

Tortoises are long-lived reptiles with a domed bony carapace, capable of moving substantial distances (but typically less than similar sized mammals and considerably slower) over time (Hailey, 1989; Nicholls, 2012). Numerous studies have evaluated tortoise spatial ecology using home ranges (e.g., Yager et al., 2007; McMaster \& Downs, 2009; Monadjem, McCleery \& Collier, 2013; DrabikHamshare \& Downs, 2017), but most studies have used traditional home range estimators that can impede inter-study comparisons. A review covering 20 years of reptile home range studies found that 
the reporting of methodological details in the majority of studies were insufficient for meaningful comparisons of home range size (Crane et al., 2021).

In Thailand, the Elongated Tortoise Indotestudo elongata (Blyth, 1854) is listed as Critically Endangered due to its limited distribution (Rahman et al., 2019). This species is often exploited via illegal markets for local bushmeat, international/regional food, exotic pet, and medicinal trade (Ihlow et al., 2016). At present, we have limited information on home range sizes for I. elongata. Studies either lack details concerning range residency, which undermines assertions that the tortoises occupied a stable home range, or the studies use a mix of wild/translocated individuals where the impacts of translocation on home range size or stability are difficult to discern (Tharapoom 1996; Ihlow et al., 2014; Ihlow et al., 2016). For our study population (Sakaerat Environmental Research Station, Nakhon Ratchasima, Thailand), we previously identified substantial individual overlap of potential movement pathways, a lack of conspecific avoidance or attraction, and potentially evidence of year-round reproductive activity (Ward et al., 2021); but have yet to explore the space requirements of this population occupying a small protected area.

Many factors can influence home range size, such as resource availability (Wasko \& Sasa, 2009) or major disturbances such as fire (Drake et al., 2015). Often however, the inherent characteristics of the individual best predict home range size; for example, larger individuals can be expected to require larger areas in order to meet their energetic requirements. Alternatively, reproductively active male tortoises may cover greater distances and move more frequently to maximise access to females. In mating systems where reproductive activity is observed year-round, such as observed for Elongated tortoises (Ward et al, 2021), we would expect substantially larger male home ranges than females unless females were also to engage in mate searching behaviour.

Here we investigate home range sizes for the Elongated tortoises in Sakaerat Environmental Research Station, Nakhon Ratchasima, Thailand. To account for the irregular sampling of our data, we use Autocorrelated Kernel Density Estimators (AKDE) as suggested by Averill-Murray, Fleming \& Riedle (2020) and Silva et al. (2021). We assess radio-tracked male and female Elongated tortoises movements for range residency (to determine if home range estimation is viable) and provide baseline estimates of home range size. Finally, we attempt to ascertain if individual differences in home range sizes are related to body size or sex.

\section{Methods}

\section{Study site}

The study took place within the core area of Sakaerat Biosphere Reserve (SBR), a UNESCO Man and Biosphere site. The site is split into three zones of varying levels of human impact: a transitional zone where agriculture and settlement are permitted, the buffer zone that is predominantly reforestation efforts, and the core zone that consists of primary forest. The protected core area is managed by Sakaerat Environmental Research Station which covers an area of approximately $80 \mathrm{~km}^{2}$ (Figure 1). The site primarily consists of seasonal dry evergreen forest and dry dipterocarp forest with patches of mixed deciduous forest and bamboo stands scattered throughout the landscape (Trisurat, 2010). We tracked all tortoises in the core area of the SBR where dry evergreen and dry dipterocarp forest merge to form an ecotone area (Ward et al., 2021). The study site also includes a small single-lane paved access road bisecting the dry dipterocarp forest to the main station grounds which are consistently occupied by staff and visitors but represent less than $1 \%$ of the overall protected area. The protected 
area of the reserve is adjacent to the major four lane highway that connects Bangkok (south) and Nakhon Ratchasima (north).
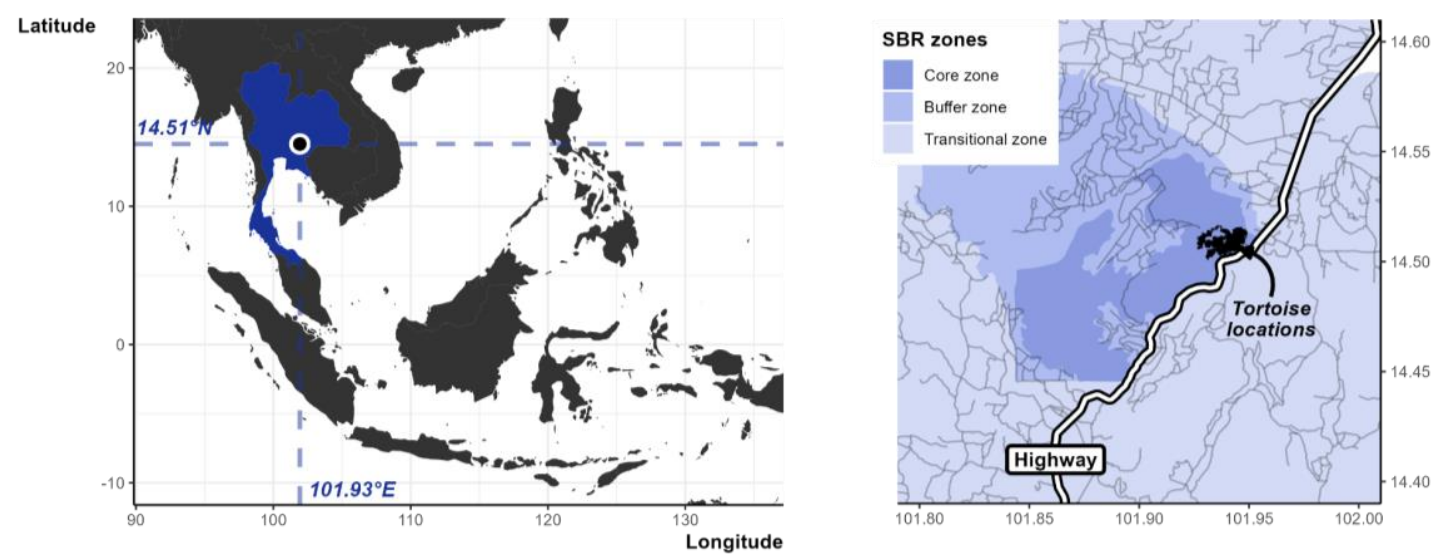

Figure 1 - Study location in Thailand. Highlighted in blue is the location of the Sakaerat Biosphere Reserve (SBR) study site: $14.51^{\circ} \mathrm{N}, 101.93^{\circ} \mathrm{E}$. The map is north orientated, $0.01^{\circ}$ latitude = approx. $1.07 \mathrm{~km}$. Second map shows the SBR in context, with the three zones making up the UNESCO Man \& Biosphere Reserve (three levels of blue shading), the highway (black and white line), and minor roads (light grey lines).

\section{Capture and radio-telemetry}

We set out to select animals using random encounter surveys, with a total of 10 individuals being sought for a telemetry period of 12 months $(n=10 ; 2016 / 17$, and $n=8,2017 / 18$, but one individual appeared in both years). We had great difficulty finding animals during the random surveys, so we supplemented this method with opportunistic findings through road encounters and through other observers who encountered individuals whilst in the reserve conducting other studies. After collecting individuals, we recorded tortoise biometric data (weight, straight carapace length, domed carapace length), took identification photos of the carapace, plastron, and face, and marked the individual with an ID number (M01 - Male 1, F01 - Female 1, etc.) using a white paint pen. After measuring and marking, we attached radio transmitters (Holohil RI-2B 9g glue mount transmitter; Holohil Systems Ltd, 2021; https://www.holohil.com/) using a non-toxic industrial epoxy (Gurit industries Ltd). Using the epoxy resin with a hardening solution (50/50 mix), we coated the underside of the transmitter and placed it firmly to the anterior scute of the animal's carapace above the head and nuchal scute. We then placed globules of the resin mix on the $20 \mathrm{~cm}$ long antenna and affixed it to the lateral scutes of the tortoise toward the posterior. The following day we released the animal at the same location where it was caught and resumed tracking the individual the day after.

We aimed to track 10 individuals, locating each individual once every two days. We undertook tracking in pairs, using one tracking radio receiver. The tracking regime was not always strictly adhered to due to team turnover, weather, and other external factors. During our second telemetry period (2017/18), we focused on female tortoises.

\section{Home range estimates}

We used Autocorrelated Kernel Density Estimators (AKDE) to calculate tortoise home ranges (Fleming \& Calabrese, 2017). The manual collection of radio-tracking data, compared to regimented or automated GPS collection methods, makes AKDE an excellent analysis method to help address unforeseen lapses in data collection (e.g., due to staffing limitations, equipment failure, or inclement 
weather) particularly with the weighted AKDE function in the ctmm package (Calabrese, Fleming \& Gurarie, 2016; Silva et al., 2021), which corrects for unrepresentative sampling in time.

We used the ctmm package (Calabrese, Fleming \& Gurarie, 2016; Fleming \& Calabrese, 2021) to generate variograms for each individual, which visualising the average square distance travelled by the individual within given time lags (termed semi-variance). Using the variograms, we visually determined which individual's movements suggested range residency (a flattening of the semivariance values), which is an assumption required for estimating home ranges with AKDEs (i.e., tortoises tend to remain within their home range areas, and do not exhibit nomadic or migratory behaviours). In further analyses we only included those ranges determined to be stable $(n=14)$. Via the ctmm package we fit a number of movement models (ctmm's default range of models) using several processes: Ornstein-Uhlenbeck (OU), Ornstein-Uhlenbeck Foraging (OUF), and Independent Identically Distributed (IID). While the IID process is analogous to a traditional KDE approach assuming independent points, the OU process accounts for a central tendency in the animal movement (i.e., range residency or home range). The OUF process is largely similar to OU but also accounts for autocorrelative structures in the velocity of movement. We fit each of these processes in two forms: isotropic and anisotropic, to cover instances where the home range may be more circular or elliptical, respectively.

We fit the movement models (using all of the aforementioned processes) using the perturbative hybrid residual maximum likelihood method (pHREML; Fleming et al., 2019) and used AICc to select the best fitting movement model for each individual. We also recovered the home range crossing time and effective sample sizes (approximately the tracking duration divided by average home range crossing time; Silva et al., 2021). Effective sample size highlights the amount of information available to the home range estimator once redundant location information resulting from autocorrelation is accounted for. Finally, we estimate weighted AKDE home range areas (Silva et al., 2021), selecting the 95\% contour to represent their home range area and using the point estimate of the $95 \%$ contour for comparisons.

\section{Comparisons}

Due to the small sample size, and lack of a priori hypotheses, we elected to use Bayesian tests of difference to explore how home range size differed between sexes, and in relation to mass (Ellison, 2004). We used the same Bayesian methods to describe differences in mass and carapace length between the sexes. We used a student t-distribution as the response distribution, and the three model formulae were:

\section{AKDE $95 \%$ contour point estimate $\sim 0+$ sex, sigma $\sim$ sex}

2. Mass $\sim 0+$ sex, sigma $\sim \operatorname{sex}$

\section{Carapace length $\sim 0+$ sex, sigma $\sim$ sex}

We used weakly informative priors for the three models, based upon means and spreads reported in a previous publication concerning these tortoises (Ward et al., 2021). For a prior describing the home range estimates, we used the previously reported dynamic Brownian Bridge Movement Model (dBBMM) 95\% confidence areas - mean of 26.17 ha, standard deviation (SD) of 33.48 ha (Ward et al., 2021). Although dBBMM estimates do not target home ranges like AKDEs, the way dBBMM confidence areas describe the uncertainty associated with the animal's movement path (calibrated by the animal's movement capacity) can help infer an animal's overall space requirements. We set the 
carapace length prior to a mean of $37.1 \mathrm{~cm}$ and SD of $4.37 \mathrm{~cm}$; and we set the mass prior to a mean of $1.75 \mathrm{~kg}$ and SD of $0.5 \mathrm{~kg}$. All three priors were normally distributed with a lower bound limit of 0 . For the spread we used two standard deviations to weaken the strength of the prior.

We ran the models with the following setting: 4 chains, 2000 iterations, and 1000 iterations of warmup. Due to convergence issues, we modified two MCMC settings: we increased the adaptive delta to 0.90 , and the maximum tree depth to 15 .

We also ran a model to explore the relationship between home range area and mass. We included a group effect to account for the possible non-independence of home range sizes within each sex. Our final formula was: AKDE 95\% contour point estimate $\sim 1+$ Mass $+(1 \mid \operatorname{sex})$. As we had less prior knowledge concerning the home range mass relationship, we elected to use a very weakly informative prior to constrain the beta coefficient describing the effect of mass (Lemoine, 2019): a Cauchy prior with location 0.1 and scale 5 . We ran this model using different settings due to the increased difficulty for the model to satisfactorily converge: 4 chains, 8000 iterations, 2500 warmup iterations, and adaptive delta of 0.95 , and a maximum tree depth of 15 .

For all models, we used $\hat{R}$ values $(\sim 1)$, trace plots, acf plots, and posterior predictive check plots to check model convergence (see https://osf.io/rxu6f/).

\section{Results}

\section{Tracking summary}

We tracked 17 individuals ( 12 females, 5 males) for a mean of $353.76 \pm 33.10$ days (range 279-870; Figure S1). We found tortoises frequently relocated between subsequent data points, with a mean of $98.47 \pm 7.73$ moves (range 64-211) compared to a mean of $115.35 \pm 7.94$ data points (range 88-227; Table 1). The gap between each data point was approximately $74.25 \pm 3.13$ hours (range 24-5712; the largest gap was the lag between F05 tracking in 2016/17 and 2017/18; Figure S2).

Table 1 - Tracking summary by individual. \pm indicate standard error associated with means.

\begin{tabular}{ccccccc} 
ID & $\begin{array}{c}\text { Data } \\
\text { points }\end{array}$ & Start date & End date & $\begin{array}{c}\text { Days } \\
\text { tracked }\end{array}$ & $\begin{array}{c}\text { Tracking } \\
\text { time lag } \\
\text { (hour) }\end{array}$ & Moves \\
\hline F01 & 119 & $2016-03-16$ & $2017-03-16$ & 365 & $74.24 \pm 4.63$ & 94 \\
F02 & 111 & $2016-03-23$ & $2017-02-28$ & 342 & $74.62 \pm 8.1$ & 86 \\
F03 & 121 & $2016-04-10$ & $2017-03-19$ & 343 & $68.6 \pm 5.19$ & 108 \\
F04 & 122 & $2016-04-08$ & $2017-03-18$ & 344 & $68.23 \pm 4.46$ & 115 \\
F05 & 227 & $2016-04-08$ & $2018-08-26$ & 870 & $92.39 \pm 25.15$ & 211 \\
F06 & 98 & $2017-10-22$ & $2018-08-28$ & 310 & $76.7 \pm 5.04$ & 94 \\
F08 & 99 & $2017-10-22$ & $2018-08-31$ & 313 & $76.65 \pm 4.72$ & 95 \\
F09 & 102 & $2017-10-27$ & $2018-08-26$ & 303 & $72 \pm 3.17$ & 99
\end{tabular}




$\begin{array}{lcccccc}\text { F10 } & 90 & 2017-11-21 & 2018-08-31 & 283 & 76.31 \pm 4.55 & 76 \\ \text { F12 } & 88 & 2017-11-14 & 2018-08-28 & 287 & 79.17 \pm 5.32 & 78 \\ F 14 & 89 & 2017-11-21 & 2018-09-01 & 284 & 77.45 \pm 5.27 & 80 \\ \text { F15 } & 90 & 2017-11-22 & 2018-08-28 & 279 & 75.24 \pm 4.9 & 64 \\ \text { M01 } & 128 & 2016-03-16 & 2017-03-16 & 365 & 68.98 \pm 4.39 & 101 \\ \text { M03 } & 129 & 2016-04-01 & 2017-03-19 & 352 & 66 \pm 4.33 & 84 \\ \text { M04 } & 124 & 2016-04-05 & 2017-03-21 & 350 & 68.29 \pm 5.26 & 103 \\ \text { M05 } & 130 & 2016-04-16 & 2017-03-19 & 337 & 62.7 \pm 4.26 & 105 \\ \text { M06 } & 94 & 2016-06-03 & 2017-03-17 & 287 & 74.06 \pm 6.32 & 81\end{array}$

\section{Home range}

Despite the mean lag time between tracks being over three days ( 74.25 hours) and high uncertainty associated with semi-variance (e.g., F03 and F06 variograms), we found that 14 out of 17 individuals' ranges appear to be stable -therefore, meeting the range residency assumption required for AKDE home range estimation (Figure 2). On average the home range crossing time was $17.24 \pm 4.37$ days, with considerable individual variation (2.71-72.25 days). Males had lower home range crossing times (6.51 \pm 1.48 days) than females (21.70 \pm 5.73 days). Effective sample size for home range estimation was on average $29.48 \pm 4.97$, justifying the use of pHREML fitting method and weighting the AKDE areas (Silva et al., 2021). Effective sample size ranged from 3.39 to 75.06, and four individuals had exceptionally low effective sample sizes (<10: F06, F08, F10, F12; Table S2). The low effective sample sizes mirror the lack of stability displayed in the variograms of F08, F10, and F12, and supported our exclusion of these individuals for further analysis. 

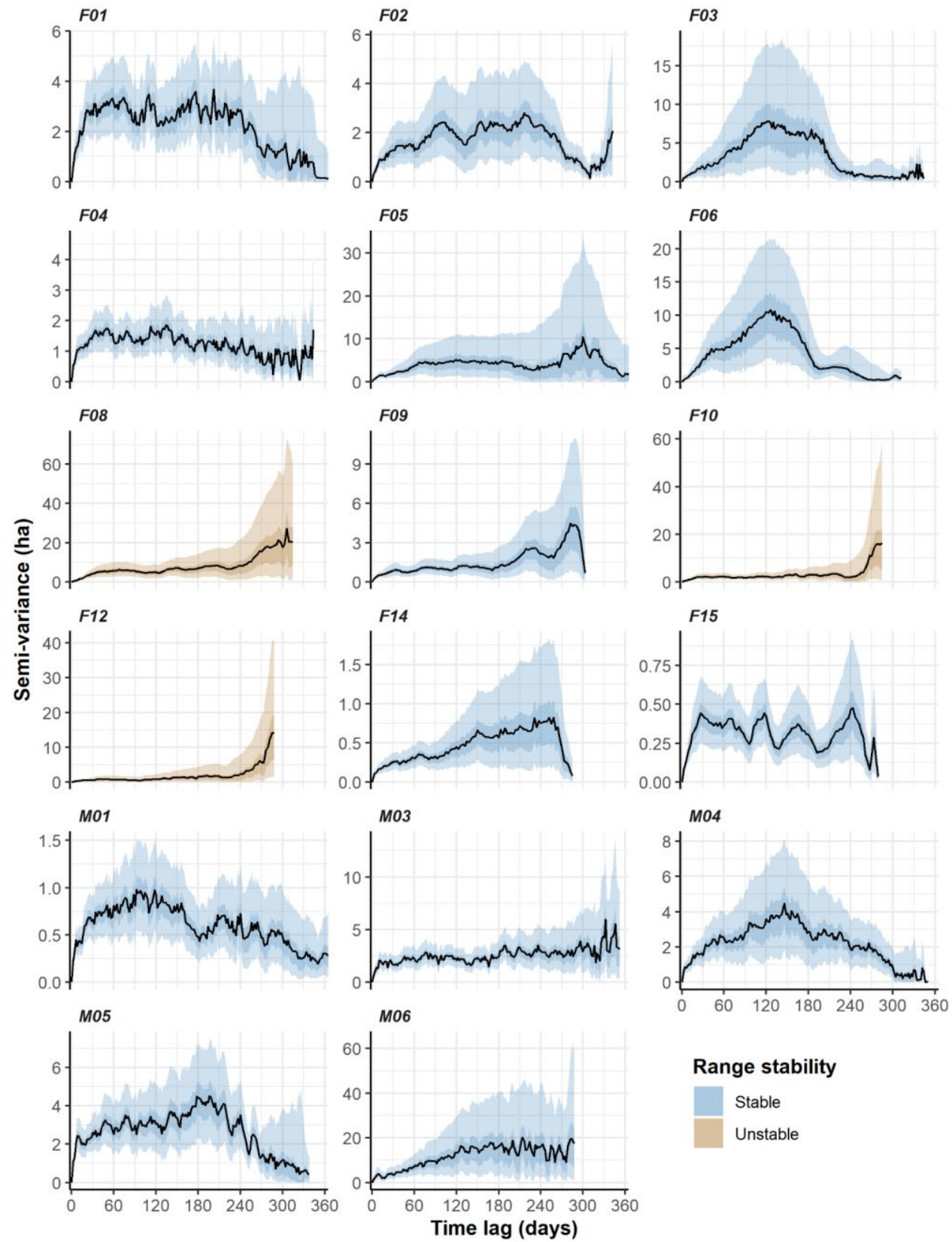

Figure 2 - Variograms displaying semi-variance of home range area estimates with $x$-axis starting at the beginning of each individual's tracking period. Shaded areas display the 50\% (dark shading) and 95\% (light shading) confidence intervals. Blue coloured areas are ranges considered stable; orange coloured areas are ranges considered unstable.

The 14 individuals who met the range residency assumption suggest a mean 95\% contour home range of $44.81 \pm 10.44$ ha (varying between the lowest CI of 2.99 ha and a maximum CI 415.36 ha; Figure 3; Table 2). The top performing movement models selected were either Ornstein-Uhlenbeck (OU) or Ornstein-Uhlenbeck foraging process (OUF), which correspond to correlated positions but uncorrelated velocities, or correlated positions and correlated velocities, respectively (Table S3). Both movement models incorporate restricted space use. Five of the 17 individuals had multiple models within 2 delta AICc (Table S3), but three of these were the non-range resident individuals. The remaining two were F06 where OU AICc was 1.3 lower than OUF, and F09 where both models were $\mathrm{OU}$, and only differed in reflecting more isotropic (more circular) versus anisotropic (more elliptical; delta AICc of 1.5) home ranges. Models that relied on assumptions of Independent Identically 
Distributed data (IID; i.e., traditional KDE approach) consistently produced the highest dAICc values (Table S2).

Table 2 - Autocorrelated Kernel Density Estimate (AKDE) results per range resident individual and the movement model used to produce the estimate. Also included are the morphometric data (mass and carapace length). Lower and upper confidence intervals are $95 \%$. AKDE estimates are in hectares.

\begin{tabular}{ccccccc} 
ID & $\begin{array}{c}\text { Mass } \\
(\mathbf{k g})\end{array}$ & $\begin{array}{c}\text { Carapace } \\
\text { length }(\mathbf{c m})\end{array}$ & $\begin{array}{c}\text { AKDE } \\
\text { lower CI }\end{array}$ & $\begin{array}{c}\text { AKDE } \\
\text { estimate }\end{array}$ & $\begin{array}{c}\text { AKDE } \\
\text { upper CI }\end{array}$ & $\begin{array}{c}\text { Movement } \\
\text { Model }\end{array}$ \\
\hline F01 & 1.5 & 37.1 & 30.31 & 45.66 & 64.1 & OU anisotropic \\
$F 02$ & 1.82 & 37.2 & 17.35 & 25.3 & 34.72 & OU isotropic \\
$F 03$ & 1.73 & 38.6 & 29.4 & 48.77 & 72.97 & OU anisotropic \\
$F 04$ & 1.72 & 37.9 & 16.3 & 21.61 & 27.65 & OU anisotropic \\
$F 05$ & 1.85 & 37.2 & 24.75 & 34.74 & 46.4 & OU anisotropic \\
$F 06$ & 1.53 & 36.2 & 32.05 & 86.85 & 168.49 & OU anisotropic \\
$F 09$ & 1.67 & 35.9 & 11.73 & 18.81 & 27.54 & OU isotropic \\
$F 14$ & 1.25 & 32.1 & 4.2 & 6.56 & 9.45 & OU isotropic \\
$F 15$ & 1.6 & 33 & 2.99 & 4.67 & 6.7 & OU anisotropic \\
M01 & 2.07 & 40.3 & 9.47 & 12.84 & 16.72 & OU anisotropic \\
M03 & 1.84 & 38.5 & 31.16 & 40.94 & 52.03 & OU anisotropic \\
M04 & 1.79 & 38.2 & 28.07 & 40.63 & 55.48 & OU anisotropic \\
M05 & 1.54 & 36.8 & 31.2 & 39.66 & 49.12 & OU anisotropic \\
M06 & 2.05 & 39.7 & 61.47 & 101.12 & 150.49 & OU anisotropic
\end{tabular}


F01

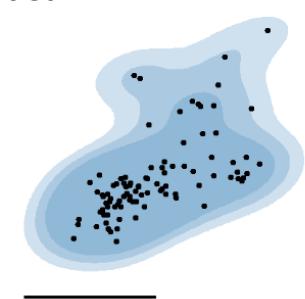

F04

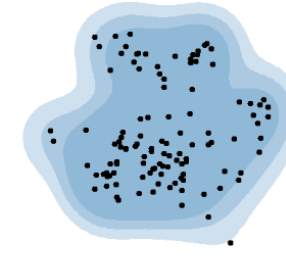

F08

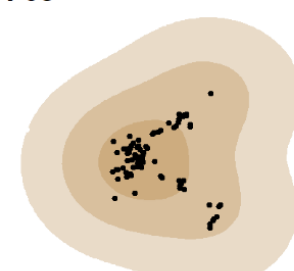

F12

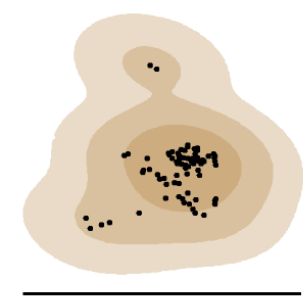

M01

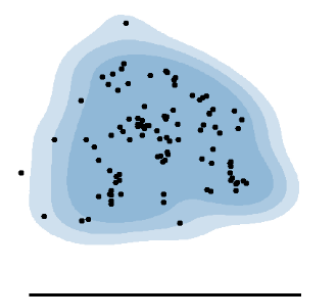

M05

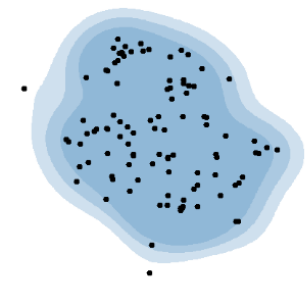

F02

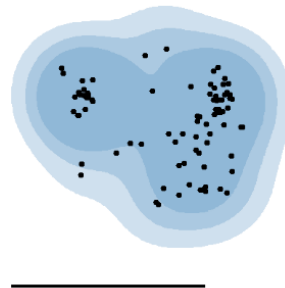

F05

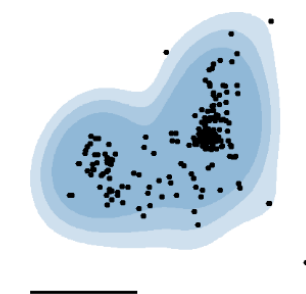

F09

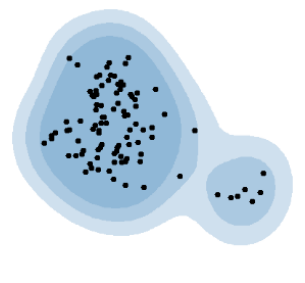

F14

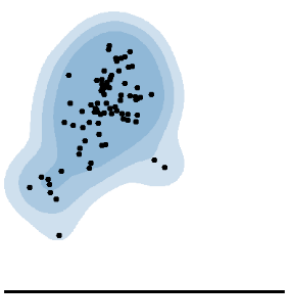

M03

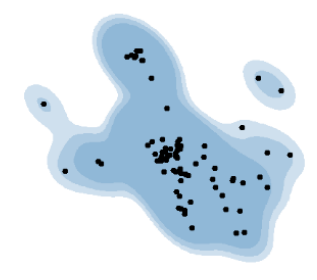

M06

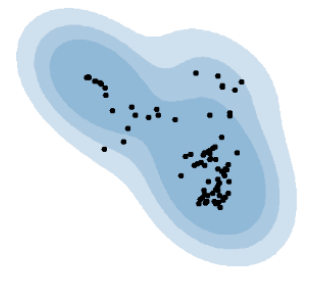

F03

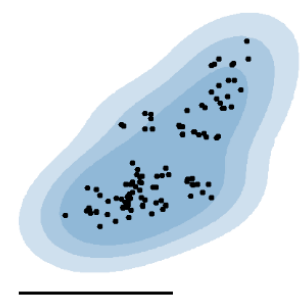

F06

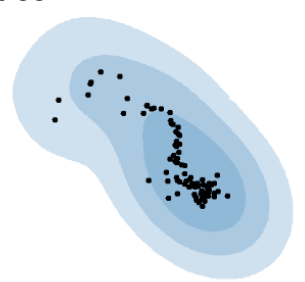

F10

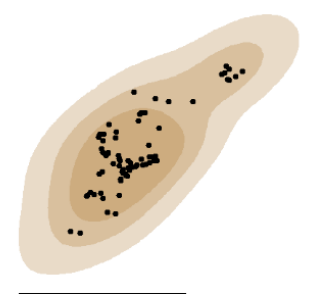

F15

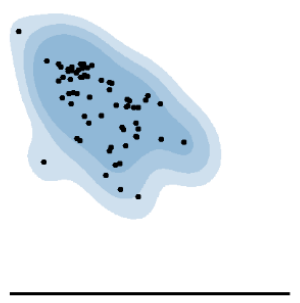

M04

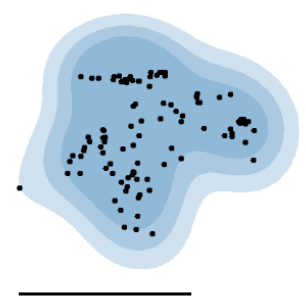

\section{Range stability}

Stable

Unstable

Figure 3 - The 95\% contour AKDE area estimates mapped. Upper 95\% confidence level is shown with the darkest shading, the mean point estimate is shown with a medium level of shading, and the lower $95 \%$ confidence interval is shown with the lightest shading. Scale bars represent $500 \mathrm{~m}$. Blue coloured areas are ranges considered stable; orange coloured areas are ranges considered unstable. 


\section{Comparisons}

The AKDE area estimates did not differ substantially between males and females. Although female ranges were on average $11.09 \pm 16.62$ ha smaller, the 95\% Highest Density Interval (HDI) suggest that male ranges could be up to 43.66 ha larger, or up to 21.84 ha smaller than female ranges. The wide HDI can be summarised as a $75.23 \%$ chance that males have a larger range (Figure 4).

Carapace length was considerably more different, with females on average having a $2.34 \pm 1.13 \mathrm{~cm}$ shorter carapace (95\% HDI 0.21-4.60) and a $97.95 \%$ chance that males have a longer carapace. Mass showed a similar pattern. On average females weighed $0.22 \pm 0.14 \mathrm{~kg}$ less (95\% HDI 0.5 lighter-0.04 heavier), resulting in a $94.63 \%$ chance for males to weigh more (Figure 4).

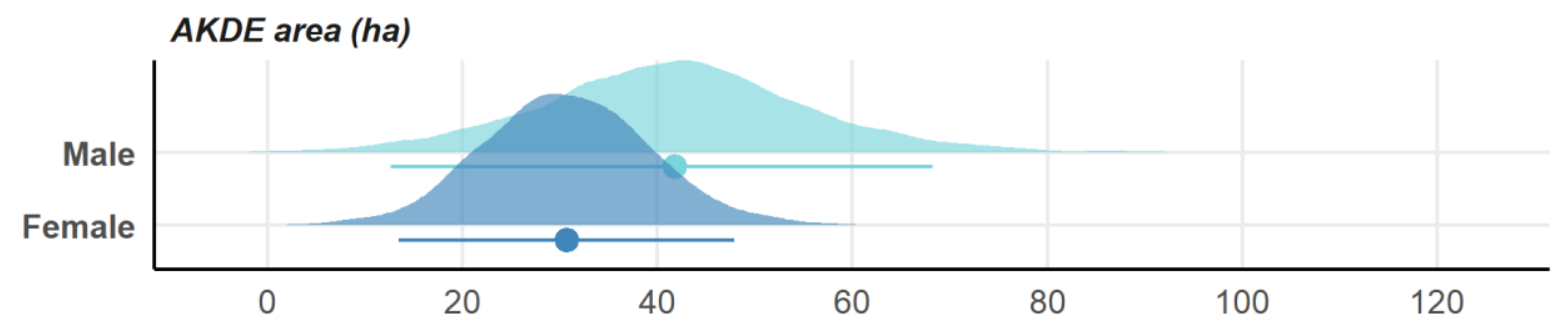

Carapace length $(\mathrm{cm})$

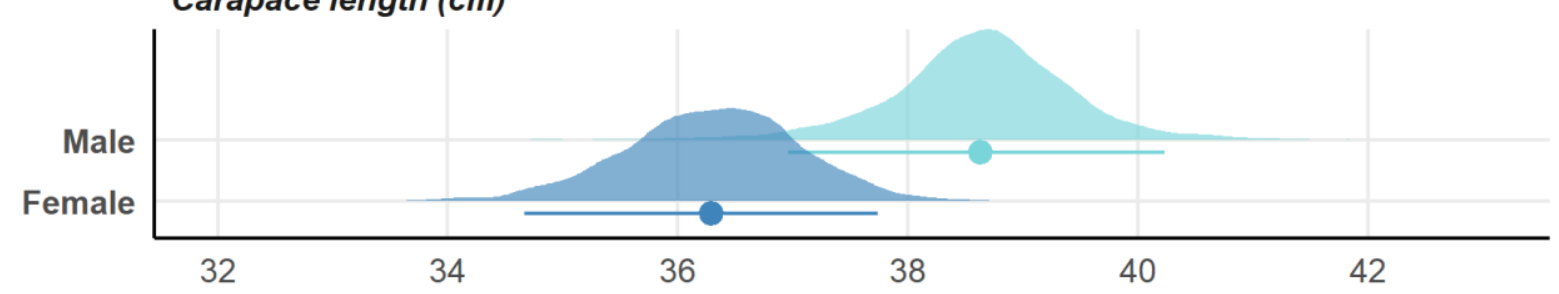

Mass (kg)

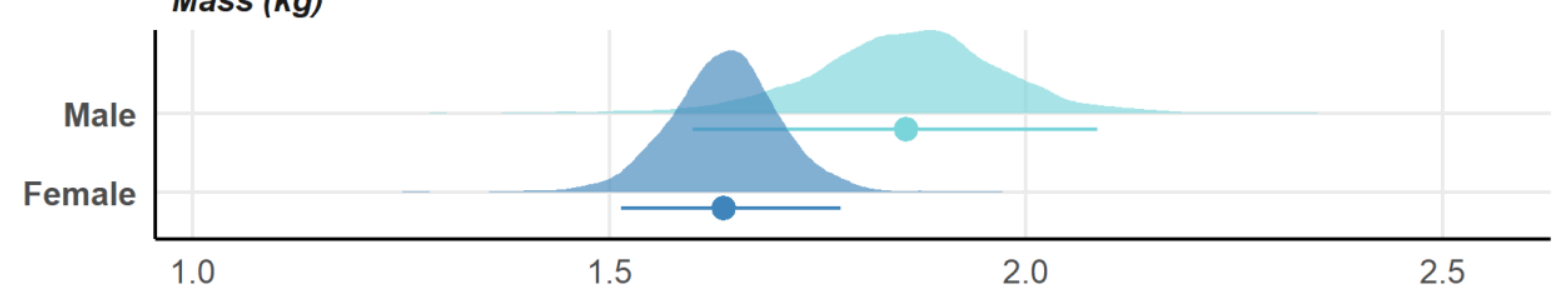

Figure 4 - Bayesian comparisons between Female and Male tortoises with stabilised ranges. Point estimates are displayed with 95\% mean Highest Density Continuous Intervals.

The exploration of mass and AKDE area reveal a minor positive relationship between mass and AKDE area $(\beta=2.88)$. However, the credible intervals were wide (95\% CRI -19.74-37.05; Figure 5) and the $R^{2}$ values were exceptionally low (Conditional $R^{2}: 0.022$, Marginal $R^{2}: 0.001$ ) suggesting the model fails to capture any important variation in home range sizes. 


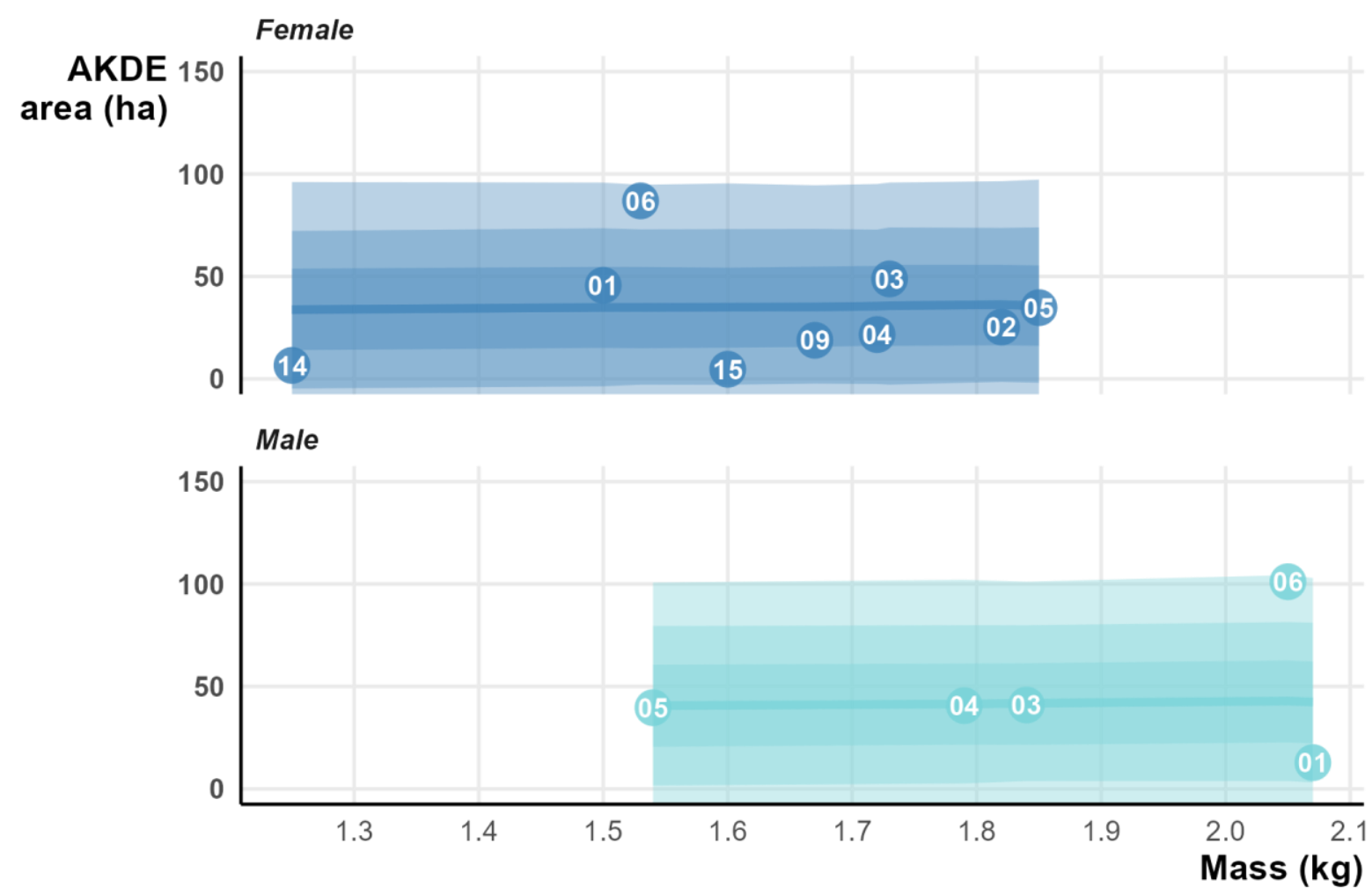

Figure 5 - 95\% contour AKDE area in relation to the mass ( $\mathrm{kg}$ ) of female (dark blue) and male (light blue) tortoises. Points are the recorded mass and areas of all individuals with their ID number. Shaded areas indicate the 95\% (lightest shading), $80 \%$ (medium shading), 50\% credible intervals (darkest shading).

\section{Discussion}

We described the home range of a Critically Endangered tortoise species (Indotestudo elongata) using a modern home range estimation method (Autocorrelated Kernel Density Estimators [AKDE]) that is capable of mitigating the biases stemming from low-resolution (and low effective sample size) telemetry data. We found that variograms indicated range residency for 14 of 17 tracked tortoises. While Bayesian Regression Models revealed that both mass and carapace length were larger for male tortoises, the AKDE ranges appeared on average only slightly larger for males and are broadly comparable with female tortoise ranges.

Generally, in testudines, there is a slight dimorphism in body size with males being larger than females. This size difference is more apparent in giant tortoise clades, such as the Galapagos and Aldabra tortoises (Chiari et al., 2009; Turnbull et al., 2015), but less apparent in mid-sized forest dwelling species of the tropics including I.elongata. Our evidence suggests tracked male individuals were larger than females, which is in line with an earlier study on the same species (Ihlow et al., 2016). However, given the lack of published information on I. elongata and due to potential impacts of harvesting, quantifying the size and age ratio (and observable dimorphism from that) within a population remains challenging. In some areas there is no difference between the sizes in adult males or females; however, without accurate age measurement it is impossible to discern whether individuals are still growing adults or at full size (Sriprateep et al., 2013).

As semi-variance represents the average square distance within all given time lags, it ultimately measures the spatial variability in movement behaviour. For short time lags, upward curvature of semi-variance indicates directional persistence. When the semi-variance spikes across intermediate 
time lags it indicates comparatively faster diffusive behaviour (the animal is covering greater distances), whereas spikes in the furthest/longest time lags typically correlate with migration or range shifting behaviour. While we are unable to pinpoint the cause of the spikes, seasonal variation is a likely candidate. Our study site sees strong seasonal shifts in rainfall that brings forth new vegetative growth, fungal blooms, and I. elongata breeding activity (Ihlow et al., 2016, Ward et al., 2021). This species is said to be a water loving testudine, with many anecdotal reports of I. elongata frequenting bathing locations and favouring wetlands or riparian habitats where it can be semi-submerged (Ihlow et al., 2016; Ward, 2018). We did not record many areas of such habitats within the current study site, so it is possible that during the heavy rains the tortoises moved into areas of softer clay, shallow pools, or ditches where they could wallow.

As we found an exceptionally low $\mathrm{R}^{2}$ value while attempting to predict home range sizes based on either tortoise size or sex, we suspect there are alternative, more direct drivers of home range sizes. For example, some individuals spent substantial time along dry stream beds with steep slopes that may have limited movement in certain directions. Other individuals used more complex landscape features; for example, ecotone areas between deciduous dipterocarp forests and dry evergreen forests that could have influenced movements and the resulting home range estimates (Heit, Ortiz-Calo \& Montgomery, 2021). Other factors that may have influenced home range variation - that we were unable to capture with our models and the resolution of our tracking data - could be seasonal shifts in resource availability (e.g., water access, usually provided by depressions along rocks) that might lead tortoises to concentrate movements toward, or cease movements once arriving at, these temporary resources.

Following the suggestions of the STRANGE framework (Webster \& Rutz, 2020), we highlight a number of limitations regarding the sampling. The number of animals we could feasibly work with and the absolute (and effective sample size) resulting from our achieved tracking regime limit the inferences we can draw. We conducted this study with a revolving team (of which only two individuals were consistently present) both surveying for study animals and tracking animals. The cryptic camouflage of the carapace in the target species made finding the target species purely via systematic or random surveying unfeasible. We were able to supplement these randomly encountered individuals with animals encountered on the main access road to Sakaerat Environmental Research Station or brought to us by personnel in the area. However, with a limited team and up to 10 simultaneously tracked animals we were limited in the tracking interval we could logistically implement. The initial goal of once-per-two-day tracking became more difficult over time as a result of team turnover. The training period required for new team members ultimately resulted in a team with the capacity to track three individuals per day, thereby limiting each tortoise to three tracks per week. With the inconsistencies of trackers and the occasional absences of members through sickness, conferences, or vacations, we produced an inconsistent tracking regime (much like what typically occurs in other radio-tracking studies). Rainy seasons further introduced heterogeneity into our tracking regime, as we were forced to alter protocols to both protect our equipment and keep up with highly mobile animals post rain. The radio-tracking receivers, antennas and accessories are all highly susceptible to water damage, and high humidity causes interference with the radio signal - the latter led to lost animals on numerous occasions. These inconsistencies violate the assumptions of traditional Kernel Density Estimators and make Minimum Convex Polygons fraught with difficulty (due to lack of comparability with other studies that had consistent or differing tracking regimes).

Even with tracking inconsistencies, we were able to yield biologically useful results for 14 of 17 individuals using AKDEs and bias-mitigating measures (pHREML fitting and area weighting). Thereby, providing further evidence that barriers caused by logistic constraints may be overcome 
when the resulting heterogeneity in sampling are accounted for appropriately. The home range estimates we provide could be used to inform the space requirements for I. elongata in protected areas comparable to the Sakaerat Biosphere Reserve, while also providing useful priors for designing spatially explicit capture recapture studies capable of robust estimates of I. elongata populations.

\section{Acknowledgements}

We thank the Suranaree University of Technology (School of Biology, and the Institute of Research and Development) for providing the resources required to undertake this research. We thank Sakaerat Environmental Research Station (SERS) and Thailand Institute of Scientific and Technological Research (TISTR) for logistic support throughout the study and permission for site access. This work was partially funded by the Center of Advanced Systems Understanding (CASUS), which is financed by Germany's Federal Ministry of Education and Research (BMBF) and by the Saxon Ministry for Science, Culture and Tourism (SMWK) with tax funds on the basis of the budget approved by the Saxon State Parliament. We thank numerous simultaneous research teams including the Sakaerat Naja Project, King Mongkut's University of Technology, Thonburi Conservation Ecology Group, Sakaerat Conservation and Snake Education Team as well as SERS staff and visitors for helping to detect additional animals ad hoc to add to the study. We thank Anchalee Awophol for assistance in obtaining research permits for this project. We also thank both the National Research Council of Thailand (NRCT) and the Department of National Parks Thailand for permission to work with this species (Permit Number: 0002/3589). We finally thank Rachel George, Jonathan Clegg, MJ Suriyamongkol, Mark Read, Nate Quarrel, Jizel Miles, Matt Macpherson, Dani Mateo and George Wykes for their assistance in maintaining this project over a consistent two-year period through hard field days and impressive resolve when tracking wild tortoises.

\section{Data availability}

Data is available via Movebank (Study ID: 1128208874, originally published as part of Ward et al., 2021; https://www.movebank.org/; Kranstauber et al., 2011; Wikelski et al., 2021), and has been additionally published alongside analysis code and model outputs on the Open Science Framework (https://osf.io/rxu6f/). We conducted all analysis and visualisation using R v.4.0.3 (R Core Team, 2020) via RStudio v.1.4.1103 (R Studio Team, 2020). We used the R packages listed in Table S1 (with citations auto-generated using the grateful v.0.0.3 package; Rodríguez-Sánchez \& Hutchins, 2020).

\section{Funding}

National Geographic and British Chelonia Group supported field work for this project.

\section{Author contributions}

Conceptualisation - YM, MW, CTS; Methodology - YM, MW, CTS, BMM, IS; Formal analysis BMM, IS; Visualisation - BMM; Investigation - YM, MW; Resources - TA, SW; Writing-original draft - CTS, BMM, MW; Writing-review and editing - YM, MW, CTS, BMM, IS, TA, SW; Supervision - TA, SW; Funding acquisition - YM, MW

\section{Competing interests}

The authors declare no competing interests. 


\section{References}

Averill-Murray R, Fleming C, Riedle J. 2020. Reptile home ranges revisited: a case study of space use of Sonoran Desert Tortoises (Gopherus morafkai). Herpetological Conservation and Biology 15:253-271.

Breininger D, Bolt R, Legare M, Drese J, Stolen E. 2011. Factors Influencing Home-Range Sizes of Eastern Indigo Snakes in Central Florida. Journal of Herpetology 45:484-490. DOI: 10.2307/41415322.

Burt WH. 1943. Territoriality and Home Range Concepts as Applied to Mammals. Journal of Mammalogy 24:346-352. DOI: $10.2307 / 1374834$.

Calabrese JM, Fleming CH, Gurarie E. 2016. Ctmm: an R Package for Analyzing Animal Relocation Data As a ContinuousTime Stochastic Process. Methods in Ecology and Evolution 7:1124-1132. DOI: 10.1111/2041-210X.12559.

Chiari, Y, Hyseni, C, Fritts, TH, Glaberman, S, Marquez, C, Gibbs, JP, Claude, J, Caccone, A, 2009. Morphometrics parallel genetics in a newly discovered and endangered taxon of Galápagos tortoise. PLoS One, 4(7), p.e6272. DOI: 10.1371/journal.pone.0006272

Crane M, Silva I, Marshall BM, Strine CT. 2021. Lots of movement, little progress: a review of reptile home range literature. PeerJ 9:e11742. DOI: 10.7717/peerj.11742.

Di Franco A, Plass-Johnson J, Di Lorenzo M, Meola B, Claudet J, Gaines S, García-Charton J, Giakoumi S, Grorud-Colvert K, Hackradt CW, Micheli F, Guidetti P. 2018. Linking home ranges to protected area size: The case study of the Mediterranean Sea. Biological Conservation 221. DOI: 10.1016/j.biocon.2018.03.012.

Drabik-Hamshare M, Downs CT. 2017. Aspects of the home range ecology of the leopard tortoise in the semi-arid central Karoo: An area threatened with fracking. Journal of Arid Environments 144:31-41. DOI: 10.1016/j.jaridenv.2017.04.001.

Drake KK, Esque TC, Nussear KE, Defalco LA, Scoles-Sciulla SJ, Modlin AT, Medica PA. 2015. Desert tortoise use of burned habitat in the Eastern Mojave desert. The Journal of Wildlife Management 79:618-629. DOI: 10.1002/jwmg.874.

Ellison AM. 2004. Bayesian inference in ecology. Ecology Letters 7:509-520. DOI: 10.1111/j.1461-0248.2004.00603.x.

Fauvelle C, Diepstraten R, Jessen T. 2017. A meta-analysis of home range studies in the context of trophic levels: Implications for policy-based conservation. PLOS ONE 12:e0173361. DOI: 10.1371/journal.pone.0173361.

Fieberg J, Kochanny CO. 2005. Quantifying Home-Range Overlap: The Importance of the Utilization Distribution. The Journal of Wildlife Management 69:1346-1359. DOI: 10.2193/0022-541X(2005)69[1346:QHOTIO]2.0.CO;2.

Fleming CH, Calabrese JM. 2017. A new kernel density estimator for accurate home-range and species-range area estimation. Methods in Ecology and Evolution 8:571-579. DOI: 10.1111/2041-210X.12673.

Fleming, CH., Calabrese JM. 2021. Ctmm: Continuous-Time Movement Modeling. https://CRAN.Rproject.org/package $=$ ctmm.

Fleming CH, Fagan WF, Mueller T, Olson KA, Leimgruber P, Calabrese JM. 2015. Rigorous home range estimation with 
movement data: A new autocorrelated kernel density estimator. Ecology 96:1182-1188.

Fleming CH, Sheldon D, Fagan WF, Leimgruber P, Mueller T, Nandintsetseg D, Noonan MJ, Olson KA, Setyawan E, Sianipar A, Calabrese JM. 2018. Correcting for missing and irregular data in home-range estimation. Ecological Applications 28:1003-1010. DOI: 10.1002/eap.1704.

Fleming CH, Noonan MJ, Medici EP, Calabrese JM. 2019. Overcoming the challenge of small effective sample sizes in home-range estimation. Methods in Ecology and Evolution 10:1679-1689. DOI: 10.1111/2041-210X.13270.

Fraser KC, Davies KT, Davy CM, Ford AT, Flockhart DTT, Martins EG. 2018. Tracking the conservation promise of movement ecology. Frontiers in Ecology and Evolution, 6(October), 150. DOI: 10.3389/FEVO.2018.00150

Hailey A. 1989. How far do animals move? Routine movements in a tortoise. Canadian Journal of Zoology 67:208-215. DOI: $10.1139 / \mathrm{z} 89-028$.

Heit D, Ortiz-Calo W, Montgomery R. 2021. Landscape complexity persists as a critical source of bias in terrestrial animal home range estimation. Ecology. DOI: 10.1002/ecy.3427.

Holohil Systems Ltd. 2021. Transmitters. 112 John Cavanaugh Drive, Carp, Ontario. Accessed 2021-010-24. https://www.holohil.com/transmitters/

Houser AM, Somers MJ, Boast LK. 2009. Home range use of free-ranging cheetah on farm and conservation land in Botswana: research article. South African Journal of Wildlife Research - 24-month delayed open access 39:11-22. DOI: 10.10520/EJC117311.

Ihlow F, Rödder D, Bochynek T, Sothanin S, Handschuh M, Böhme W. 2014. Reinforcement as a conservation toolassessing site fidelity and movement of the endangered elongated tortoise Indotestudo elongata (Blyth, 1854). Journal of Natural History. 48(39-40):2473-85. DOI: 10.1080/00222933.2014.925595

Ihlow F, Dawson J, Hartmann T, Som S. 2016. Indotestudo elongata (Blyth 1854) - Elongated Tortoise, Yellow-headed Tortoise, Yellow Tortoise. Chelonian Conservation and Biology No. 5. DOI: 10.3854/crm.5.096.elongata.v1.2016.

Laver PN, Kelly MJ. 2008. A Critical Review of Home Range Studies. The Journal of Wildlife Management 72:290-298. DOI: $10.2193 / 2005-589$.

Lemoine NP. 2019. Moving beyond noninformative priors: why and how to choose weakly informative priors in Bayesian analyses. Oikos:oik.05985. DOI: 10.1111/oik.05985.

Linnell J, Andersen R, Kvam T, Andrén H, Liberg O, Odden J, Moa P. 2001. Home Range Size and Choice of Management Strategy for Lynx in Scandinavia. Environmental Management 27:869-879. DOI: 10.1007/s002670010195.

McMaster MK, Downs CT. 2009. Home Range and Daily Movement of Leopard Tortoises (Stigmochelys pardalis) in the Nama-Karoo, South Africa. Journal of Herpetology 43:561-569.

Mitchell MS, Powell RA. 2004. A mechanistic home range model for optimal use of spatially distributed resources. Ecological Modelling 177:209-232. DOI: 10.1016/j.ecolmodel.2004.01.015.

Mitchell MS, Powell RA. 2012. Foraging optimally for home ranges. Journal of Mammalogy 93:917-928. DOI: 10.1644/11MAMM-S-157.1. 
Monadjem A, McCleery RA, Collier BA. 2013. Activity and Movement Patterns of the Tortoise Stigmochelys pardalis in a Subtropical Savanna. Journal of Herpetology 47:237-242. DOI: 10.1670/12-070.

Nicholls, H. 2012. The legacy of Lonesome George. Nature 487, 279-280. DOI: 10.1038/487279a

Noonan MJ, Tucker MA, Fleming CH, Akre TS, Alberts SC, Ali AH, Altmann J, Antunes PC, Belant JL, Beyer D, Blaum N, Böhning-Gaese K, Cullen L, Paula RC de, Dekker J, Drescher-Lehman J, Farwig N, Fichtel C, Fischer C, Ford AT, Goheen JR, Janssen R, Jeltsch F, Kauffman M, Kappeler PM, Koch F, LaPoint S, Markham AC, Medici EP, Morato RG, Nathan R, Oliveira-Santos LGR, Olson KA, Patterson BD, Paviolo A, Ramalho EE, Rösner S, Schabo DG, Selva N, Sergiel A, Silva MX da, Spiegel O, Thompson P, Ullmann W, Zięba F, Zwijacz-Kozica T, Fagan WF, Mueller T, Calabrese JM. 2019. A comprehensive analysis of autocorrelation and bias in home range estimation. Ecological Monographs 89:e1344. DOI: 10.1002/ecm.1344.

Powell RA, Mitchell MS. 2012. What is a home range? Journal of Mammalogy 93:948-958. DOI: 10.1644/11-MAMM-S177.1 .

Rahman S, Platt K, Das I, Choudhury BC, Ahmed MF, Cota M, McCormack T, Timmins RJ, Singh S. 2019. Indotestudo elongata (errata version published in 2019). The IUCN Red List of Threatened Species 2019: e.T10824A152051190. DOI: 10.2305/IUCN.UK.2019-1.RLTS.T10824A152051190.en. Downloaded on 01 November 2021.

R Core Team. 2020. R: A language and environment for statistical computing. Vienna, Austria: R Foundation for Statistical Computing. https://www.R-project.org/.

R Studio Team. 2020. RStudio: Integrated Development Environment for R. Boston, MA: RStudio, Inc.

Rodríguez-Sánchez F, Hutchins SD. 2020. grateful: Facilitate citation of R packages.

Signer J, Fieberg JR. 2021. A fresh look at an old concept: home-range estimation in a tidy world. PeerJ 9:e11031. DOI: 10.7717/peerj.11031.

Silva I, Crane M, Marshall BM, Strine CT. 2020. Reptiles on the wrong track? Moving beyond traditional estimators with dynamic Brownian Bridge Movement Models. Movement Ecology 8:43. DOI: 10.1186/s40462-020-00229-3.

Silva I, Fleming CH, Noonan MJ, Alston J, Folta C, Fagan WF, Calabrese JM. 2021. Autocorrelation-informed home range estimation: a review and practical guide. DOI: 10.32942/osf.io/23wq7.

Sriprateep K, Aranyavalai V, Aowphol A, Thirakhupt K. 2013. Population structure and reproduction of the elongated tortoise Indotestudo elongata (Blyth 1853) at Ban Kok Village, Northeastern Thailand. Tropical Natural History. 13(1): 21-37

Tharapoom K. 1996. Radio-Telemetry study of home range size and activities of elongated tortoise Indotestudo elongata (Blyth 1853) at Huai Kha Khaeng Wildlife Sanctuary. Masters Thesis. Department of Biology, Graduate School, Chulalong University.

Trisurat Y. 2010. Land use and forested landscape changes at Sakaerat Environmental Research Station in Nakhon Ratchasima Province, Thailand. Ekologia 29:99-109. DOI: 10.4149/ekol_2010_01_99. 
Turnbull, LA, Ozgul, A, Accouche, W, Baxter, R, ChongSeng, L, Currie, JC, Doak, N, Hansen, DM, Pistorius, P, Richards, H, van de Crommenacker, J, 2015. Persistence of distinctive morphotypes in the native range of the CITES-listed Aldabra giant tortoise. Ecology and evolution, 5(23), pp.5499-5508. DOI: 10.1002/ece3.1764

Viggers KL, Hearn JP. 2005. The kangaroo conundrum: home range studies and implications for land management. Journal of Applied Ecology 42:99-107. DOI: 10.1111/j.1365-2664.2005.01001.x.

Ward M. 2018. INDOTESTUDO ELONGATA (Elongated Tortoise). UNUSUAL MORTALITY. Herpetological Review 49:108-109.

Ward M. 2021. Spatial ecology and habitat use of the critically endangered Elongated Tortoises (Indotestudo elongata) in the Sakaerat Biosphere Reserve. Masters Thesis. Department of Science, School of Biology, Suranaree University of Technology Thailand.

Ward M, Marshall BM, Hodges CW, Montano Y, Artchawakom T, Waengsothorn S, Strine CT. 2021. Nonchalant neighbors: Space use and overlap of the critically endangered Elongated Tortoise. Biotropica:btp.12981. DOI: 10.1111/btp.12981.

Wasko DK, Sasa M. 2009. Activity Patterns of a Neotropical Ambush Predator: Spatial Ecology of the Fer-de-lance (Bothrops asper, Serpentes: Viperidae) in Costa Rica. Biotropica 41:241-249. DOI: 10.1111/j.17447429.2008.00464.x.

Webster, MM, Rutz, C. 2020. How STRANGE are your study animals?, Nature, 582(7812), pp. 337-340. DOI: 10.1038/d41586-020-01751-5.

Wikelski M, Davidson SC, Kays R. 2021. Movebank: archive, analysis and sharing of animal movement data. Hosted by the Max Planck Institute of Animal Behavior. www.movebank.org, accessed on 2021-11-18.

Worton BJ. 1989. Kernel Methods for Estimating the Utilization Distribution in Home-Range Studies. Ecology 70:164-168. DOI: $10.2307 / 1938423$.

Xirouchakis SM, Grivas C, Andreou G, Georgopoulou E. 2021. Home range size, space use and resource selection of griffon vultures in an insular environment. Journal of Zoology 314:116-131. DOI: 10.1111/jzo.12868.

Yager LY, Hinderliter MG, Heise CD, Epperson DM. 2007. Gopher Tortoise Response to Habitat Management by Prescribed Burning. Journal of Wildlife Management 71:428-434. DOI: 10.2193/2006-337. 


\section{Supplementary Material}

\section{Supplementary material includes:}

Table S1 - R packages used and citations.

Table S2 - Top movement model fits and effective sample sizes.

Table S3 - All movement model fits.

Figure S1 - Sampling of data points over the three years of tracking. Colours separate individual years, and are nudged (y) to aid differentiating years.

Figure S2 - Bar plot showing the time lag in hours between tracks, with median (dotted) and mean \pm standard error (dashed) annotated.

Table S1 - R packages used and citations.

\section{Use of package Package, version, and citation}

\begin{tabular}{ll}
\hline $\begin{array}{l}\text { Data } \\
\text { manipulation }\end{array}$ & $\begin{array}{l}\text { dplyr v.1.0.2 (Wickham et al., 2020), lubridate v.1.7.9.2 (Grolemund and } \\
\text { Wickham, 2011), stringr v.1.4.0 (Wickham, 2019), reshape2 v.1.4.4 (Wickham, } \\
\text { 2007) }\end{array}$ \\
$\begin{array}{ll}\text { Home range } \\
\text { estimation }\end{array}$ & $\begin{array}{l}\text { rgdal v.1.5.18 (Bivand, Keitt, and Rowlingson, 2020), ctmm v.0.6.0 (Fleming \& } \\
\text { Calabrese, 2021), sp v.1.4.4 (Bivand, Pebesma, \& Gomez-Rubio, 2013) }\end{array}$ \\
Bayesian & bayesplot v.1.7.2 (Gabry et al., 2019), brms v.2.14.4 (Bürkner, 2018), \\
performance v.0.6.1 (Lüdecke et al., 2020), tidybayes v.2.3.1 (Kay, 2020) & \\
& cowplot v.1.1.0 (Wilke 2020a), ggplot2 v.3.3.2 (Wickham 2016), scico v.1.2.0 \\
& (Pedersen and Crameri, 2020), scales v.4.0.3 (Wickham and Seidel 2020), \\
& $\begin{array}{l}\text { ggpubr v.0.4.0 (Kassambara, 2020), ggspatial v.1.1.4 (Dunnington, 2020), } \\
\text { ggridges v.0.5.2 (Wilke, 2020b) }\end{array}$
\end{tabular}

Bivand RS, Pebesma E, Gomez-Rubio V. 2013. Applied Spatial Data Analysis with R, Second Edition. Springer, NY. https://asdar-book.org/.

Bivand R, Keitt T, Rowlingson B. 2020. Rgdal: Bindings for the 'Geospatial' Data Abstraction Library. https://CRAN.Rproject.org/package $=$ rgdal.

Bürkner PC. 2018. Advanced Bayesian Multilevel Modeling with the R Package brms. The R Journal 10 (1): $395-411$. https://doi.org/10.32614/RJ-2018-017.

Dunnington D. 2020. Ggspatial: Spatial Data Framework for Ggplot2. https://CRAN.R-project.org/package=ggspatial.

Fleming, CH., Calabrese JM. 2021. Ctmm: Continuous-Time Movement Modeling. https://CRAN.Rproject.org/package $=$ ctmm.

Gabry J, Simpson D, Vehtari A, Betancourt M, Gelman A. 2019. Visualization in Bayesian Workflow. The Journal of the Royal Statistical Society A 182: 389-402. https://doi.org/10.1111/rssa.12378.

Grolemund G, Wickham H. 2011. Dates and Times Made Easy with lubridate. Journal of Statistical Software 40 (3): 1-25. https://www.jstatsoft.org/v40/i03/. 
Kassambara A. 2020. Ggpubr: 'Ggplot2' Based Publication Ready Plots. https://CRAN.R-project.org/package=ggpubr.

Kay M. 2020. tidybayes: Tidy Data and Geoms for Bayesian Models. https://doi.org/10.5281/zenodo.1308151.

Kranstauber B, Cameron A, Weinzierl R, Fountain T, Tilak S, Wikelski M, Kays R. 2011. The Movebank data model for animal tracking. Environ Model Softw. 26(6):834-835. DOI: 10.1016/j.envsoft.2010.12.005

Lüdecke D, Makowski D, Waggoner P, Patil I. 2020. Performance: Assessment of Regression Models Performance. CRAN. https://doi.org/10.5281/zenodo.3952174.

Pedersen TL, Crameri F. 2020. Scico: Colour Palettes Based on the Scientific Colour-Maps. https://CRAN.Rproject.org/package $=$ scico .

Wickham H. 2007. Reshaping Data with the reshape Package. Journal of Statistical Software 21 (12): 1-20. http://www.jstatsoft.org/v21/i12/.

Wickham H. 2016. Ggplot2: Elegant Graphics for Data Analysis. Springer-Verlag New York. https://ggplot2.tidyverse.org.

Wickham H. 2019. Stringr: Simple, Consistent Wrappers for Common String Operations. https://CRAN.Rproject.org/package=stringr.

Wickham H, François R, Henry L, Müller K. 2020. Dplyr: A Grammar of Data Manipulation. https://CRAN.Rproject.org/package $=$ dplyr.

Wickham H, Seidel D. 2020. Scales: Scale Functions for Visualization. https://CRAN.R-project.org/package=scales.

Wilke, CO. 2020a. Cowplot: Streamlined Plot Theme and Plot Annotations for 'Ggplot2'. https://CRAN.Rproject.org/package $=$ cowplot.

Wickham H. 2020b. Ggridges: Ridgeline Plots in 'Ggplot2'. https://CRAN.R-project.org/package=ggridges.

Table S2 - Top movement model fits and effective sample sizes. dRMSPE: root mean squared prediction error

\begin{tabular}{ccccc} 
ID & $\begin{array}{c}\text { dRMSPE } \\
(\mathbf{m})\end{array}$ & $\begin{array}{c}\text { Effective } \\
\text { sample size }\end{array}$ & $\begin{array}{c}\text { Movement } \\
\text { model }\end{array}$ & $\begin{array}{c}\text { t (crossing } \\
\text { time est.; } \\
\text { days) }\end{array}$ \\
\hline F01 & 33.624 & 27.880 & OU anisotropic & 9.830 \\
F02 & 1507.207 & 32.406 & OU isotropic & 8.432 \\
F03 & 33.994 & 19.081 & OU anisotropic & 14.444 \\
F04 & 4.425 & 55.510 & OU anisotropic & 4.870 \\
F05 & 21.393 & 39.396 & OU anisotropic & 14.071 \\
F06 & 68.060 & 6.052 & OU anisotropic & 1.510 \\
F08 & 175.805 & 3.389 & OUF isotropic & 2.369 \\
F09 & 15.077 & 21.578 & OU isotropic & 12.870 \\
F10 & 44.596 & 7.793 & OU anisotropic & 24.924 \\
F12 & 54.938 & 4.894 & OU anisotropic & 1.073 \\
F14 & 8.323 & 23.865 & OU isotropic & 10.702 \\
F15 & 5.726 & 24.137 & OU anisotropic & 9.453 \\
M01 & 17.963 & 47.951 & OU anisotropic & 5.559 \\
M03 & 308.551 & 58.953 & OU anisotropic & 4.611 \\
M04 & 25.342 & 33.578 & OU anisotropic & 8.641
\end{tabular}




$\begin{array}{lcccc}\text { M05 } & 156.404 & 75.065 & \text { OU anisotropic } & 2.713 \\ \text { M06 } & 39.709 & 19.654 & \text { OU anisotropic } & 11.011\end{array}$

Table S3 - All movement model fits. Model abbreviations: Ornstein-Uhlenbeck (OU), Ornstein-Uhlenbeck Foraging (OUF), and Independent Identically Distributed (IID). dRMSPE: root mean squared prediction error.

\begin{tabular}{|c|c|c|c|c|}
\hline ID & Movement model & dAICc & dRMSPE (m) & Effective sample size \\
\hline F01 & OU anisotropic & 0.000 & 33.624 & 27.880 \\
\hline FO1 & OUF anisotropic & 2.093 & 26.715 & 33.326 \\
\hline F01 & OU isotropic & 22.806 & 30.828 & 32.089 \\
\hline F01 & OUF isotropic & 24.840 & 25.144 & 37.719 \\
\hline F01 & OUf anisotropic & 31.483 & 3.932 & 60.449 \\
\hline$F 01$ & IID anisotropic & 120.676 & 0.000 & 4.022 \\
\hline F02 & OU isotropic & 0.000 & 15.072 & 32.406 \\
\hline$F 02$ & OU anisotropic & 1.025 & 22.976 & 27.567 \\
\hline$F 02$ & OUF isotropic & 2.050 & 11.010 & 37.852 \\
\hline F02 & OUF anisotropic & 3.141 & 17.711 & 32.993 \\
\hline$F 02$ & OUf isotropic & 83.437 & 0.148 & 82.564 \\
\hline F02 & OUf anisotropic & 85.386 & 0.000 & 73.656 \\
\hline$F 02$ & IID anisotropic & 150.039 & 5.957 & 111.331 \\
\hline F02 & IID isotropic & 178.560 & 5.957 & 110.000 \\
\hline F03 & OU anisotropic & 0.000 & 33.994 & 19.081 \\
\hline F03 & OUF anisotropic & 2.060 & 24.043 & 24.664 \\
\hline F03 & OU isotropic & 3.830 & 60.740 & 17.271 \\
\hline F03 & OUF isotropic & 5.813 & 48.561 & 23.113 \\
\hline F03 & OUf anisotropic & 100.788 & 0.000 & 66.586 \\
\hline F03 & IID anisotropic & 205.322 & 31.258 & 0.091 \\
\hline F04 & OU anisotropic & 0.000 & 4.425 & 55.510 \\
\hline F04 & OUF anisotropic & 2.112 & 4.408 & 58.015 \\
\hline F04 & OU isotropic & 7.123 & 2.479 & 57.605 \\
\hline F04 & OUf anisotropic & 9.160 & 1.677 & 78.111 \\
\hline F04 & OUF isotropic & 9.250 & 2.412 & 0.000 \\
\hline F04 & IID anisotropic & 125.744 & 0.000 & 120.359 \\
\hline F05 & OU anisotropic & 0.000 & 21.393 & 39.396 \\
\hline F05 & OUF anisotropic & 2.025 & 16.855 & 45.489 \\
\hline F05 & OU isotropic & 65.668 & 59.276 & 30.744 \\
\hline
\end{tabular}




\begin{tabular}{|c|c|c|c|c|}
\hline F05 & OUF isotropic & 67.642 & 52.226 & 36.980 \\
\hline F05 & OUf anisotropic & 128.598 & 0.000 & 123.822 \\
\hline F05 & IID anisotropic & 449.476 & 36.355 & 271.801 \\
\hline F06 & OU anisotropic & 0.000 & 68.060 & 6.052 \\
\hline F06 & OUF anisotropic & 1.304 & 65.475 & 6.589 \\
\hline F06 & OU isotropic & 8.939 & 118.995 & 5.054 \\
\hline F06 & OUF isotropic & 9.974 & 113.467 & 5.584 \\
\hline F06 & OUf anisotropic & 43.919 & 0.000 & 28.361 \\
\hline F06 & IID anisotropic & 276.214 & 9.472 & 1.539 \\
\hline F08 & OUF isotropic & 0.000 & 175.805 & 3.389 \\
\hline F08 & OUF anisotropic & 0.883 & 165.078 & 3.616 \\
\hline F08 & OU isotropic & 3.262 & 213.652 & 2.704 \\
\hline F08 & OU anisotropic & 4.252 & 199.564 & 2.865 \\
\hline F08 & OUf isotropic & 46.725 & 0.000 & 29.446 \\
\hline F08 & OUf anisotropic & 47.680 & 1.522 & 29.471 \\
\hline F09 & OU isotropic & 0.000 & 15.077 & 21.578 \\
\hline F09 & OU anisotropic & 1.488 & 16.640 & 19.648 \\
\hline F09 & OUF isotropic & 2.026 & 10.003 & 27.448 \\
\hline F09 & OUF anisotropic & 3.592 & 10.909 & 25.363 \\
\hline F09 & OUf isotropic & 27.047 & 1.772 & 51.849 \\
\hline F09 & OUf anisotropic & 29.286 & 0.000 & 46.758 \\
\hline F09 & IID anisotropic & 174.144 & 6.239 & 97.592 \\
\hline F09 & IID isotropic & 201.718 & 6.239 & 101.000 \\
\hline F10 & OU anisotropic & 0.000 & 44.596 & 7.793 \\
\hline F10 & OUF anisotropic & 1.354 & 40.370 & 8.862 \\
\hline$F 10$ & OUf anisotropic & 28.388 & 0.000 & 36.588 \\
\hline$F 10$ & OU isotropic & 39.546 & 95.097 & 4.939 \\
\hline$F 10$ & OUF isotropic & 39.689 & 82.272 & 6.189 \\
\hline$F 10$ & IID anisotropic & 225.794 & 35.029 & 0.010 \\
\hline$F 12$ & OU anisotropic & 0.000 & 54.938 & 4.894 \\
\hline$F 12$ & OUF anisotropic & 1.667 & 45.091 & 5.989 \\
\hline$F 12$ & OUf anisotropic & 17.334 & 0.000 & 34.121 \\
\hline$F 12$ & OU isotropic & 34.504 & 116.055 & 2.762 \\
\hline$F 12$ & OUF isotropic & 35.932 & 91.230 & 3.605 \\
\hline
\end{tabular}




\begin{tabular}{|c|c|c|c|c|}
\hline$F 12$ & IID anisotropic & 195.824 & 9.209 & 91.148 \\
\hline$F 14$ & OU isotropic & 0.000 & 8.323 & 23.865 \\
\hline$F 14$ & OUF isotropic & 2.060 & 5.715 & 29.443 \\
\hline$F 14$ & OU anisotropic & 4.224 & 7.550 & 21.428 \\
\hline$F 14$ & OUF anisotropic & 6.372 & 4.577 & 26.804 \\
\hline$F 14$ & OUf isotropic & 29.190 & 3.452 & 48.883 \\
\hline$F 14$ & OUf anisotropic & 31.254 & 0.000 & 43.509 \\
\hline$F 14$ & IID isotropic & 151.787 & 4.408 & 88.000 \\
\hline$F 15$ & OU anisotropic & 0.000 & 5.726 & 24.137 \\
\hline F15 & OUF anisotropic & 2.158 & 3.596 & 24.701 \\
\hline$F 15$ & OU isotropic & 4.729 & 11.146 & 22.071 \\
\hline$F 15$ & OUF isotropic & 6.649 & 10.840 & 23.092 \\
\hline$F 15$ & OUf anisotropic & 20.244 & 0.000 & 46.213 \\
\hline$F 15$ & IID anisotropic & 113.479 & 7.936 & 7.692 \\
\hline M01 & OU anisotropic & 0.000 & 17.963 & 47.951 \\
\hline$M 01$ & OUF anisotropic & 2.120 & 15.824 & 53.174 \\
\hline M01 & OU isotropic & 14.747 & 6.040 & 63.448 \\
\hline M01 & OUF isotropic & 16.815 & 4.878 & 68.085 \\
\hline$M 01$ & OUf anisotropic & 47.466 & 3.072 & 94.968 \\
\hline$M 01$ & IID anisotropic & 105.411 & 0.000 & 126.984 \\
\hline M03 & OU anisotropic & 0.000 & 3.086 & 58.953 \\
\hline M03 & OUF anisotropic & 2.134 & 0.756 & 63.816 \\
\hline M03 & OUf anisotropic & 28.546 & 0.000 & 88.560 \\
\hline M03 & OU isotropic & 38.360 & 2.791 & 59.375 \\
\hline M03 & OUF isotropic & 40.426 & 0.496 & 64.203 \\
\hline M03 & IID anisotropic & 157.610 & 7.146 & 106.979 \\
\hline M04 & OU anisotropic & 0.000 & 25.342 & 33.578 \\
\hline M04 & OUF anisotropic & 2.107 & 20.203 & 39.152 \\
\hline M04 & OU isotropic & 6.519 & 22.677 & 34.344 \\
\hline M04 & OUF isotropic & 8.555 & 17.762 & 39.911 \\
\hline M04 & OUf anisotropic & 67.749 & 11.001 & 78.422 \\
\hline M04 & IID anisotropic & 188.051 & 0.000 & 121.813 \\
\hline M05 & OU anisotropic & 0.000 & 1.564 & 75.065 \\
\hline M05 & OUF anisotropic & 2.144 & 0.168 & 79.262 \\
\hline
\end{tabular}




$\begin{array}{lcccc}\text { M05 } & \text { OU isotropic } & 2.598 & 11.729 & 73.186 \\ \text { M05 } & \text { OUF isotropic } & 4.675 & 9.988 & 77.304 \\ \text { M05 } & \text { OUf anisotropic } & 25.039 & 0.000 & 108.941 \\ \text { M05 } & \text { IID anisotropic } & 63.634 & 15.464 & 134.900 \\ \text { M06 } & \text { OU anisotropic } & 0.000 & 39.709 & 19.654 \\ \text { M06 } & \text { OUF anisotropic } & 2.124 & 25.472 & 24.968 \\ \text { M06 } & \text { OU isotropic } & 29.332 & 102.924 & 16.161 \\ \text { M06 } & \text { OUF isotropic } & 31.346 & 82.023 & 21.755 \\ \text { M06 } & \text { OUf anisotropic } & 52.939 & 0.000 & 57.127 \\ \text { M06 } & \text { IID anisotropic } & 137.127 & 32.798 & 4.336\end{array}$

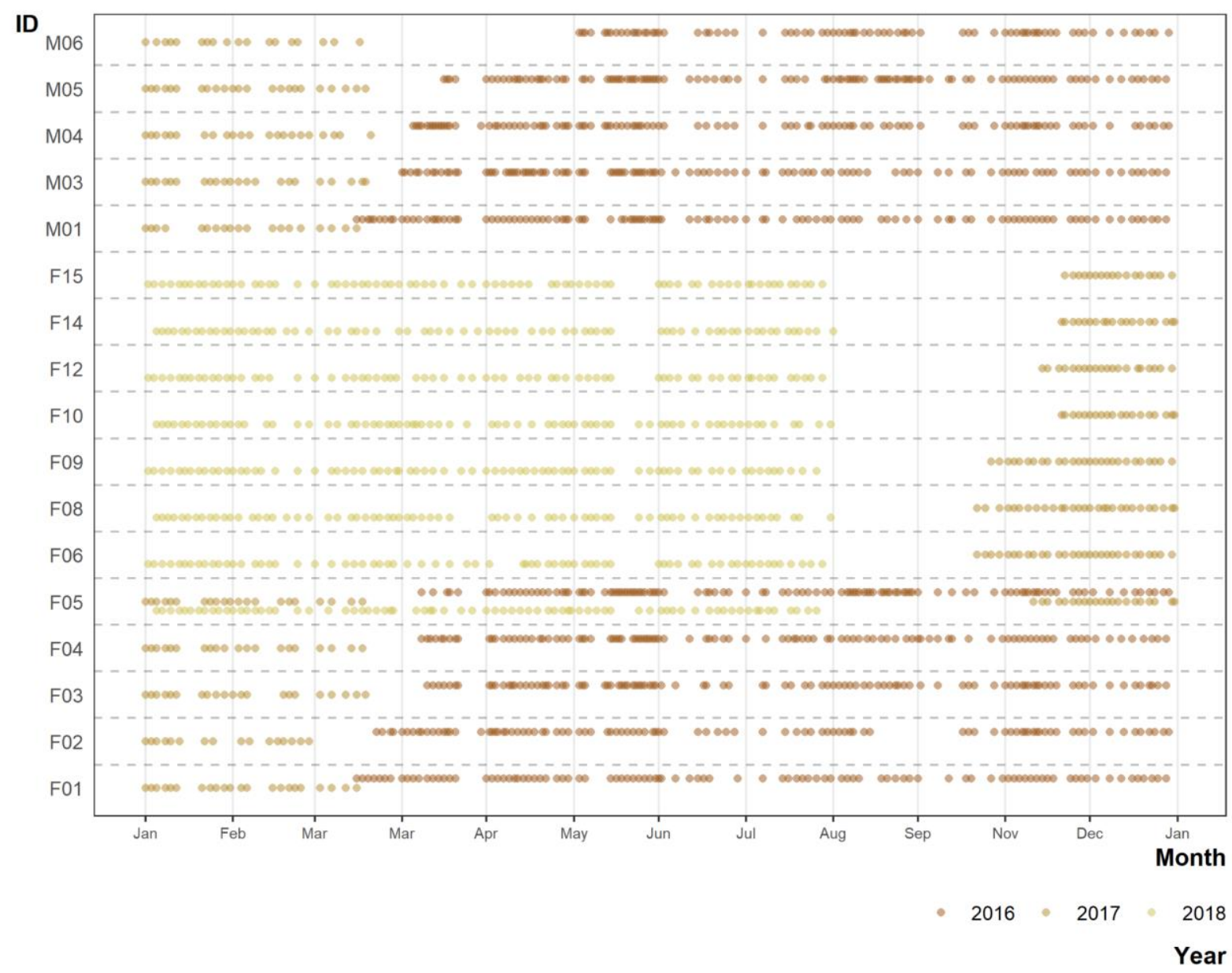

Figure S1 - Sampling of data points over the three years of tracking. Colours separate individual years, and are nudged (y) to aid differentiating years. 


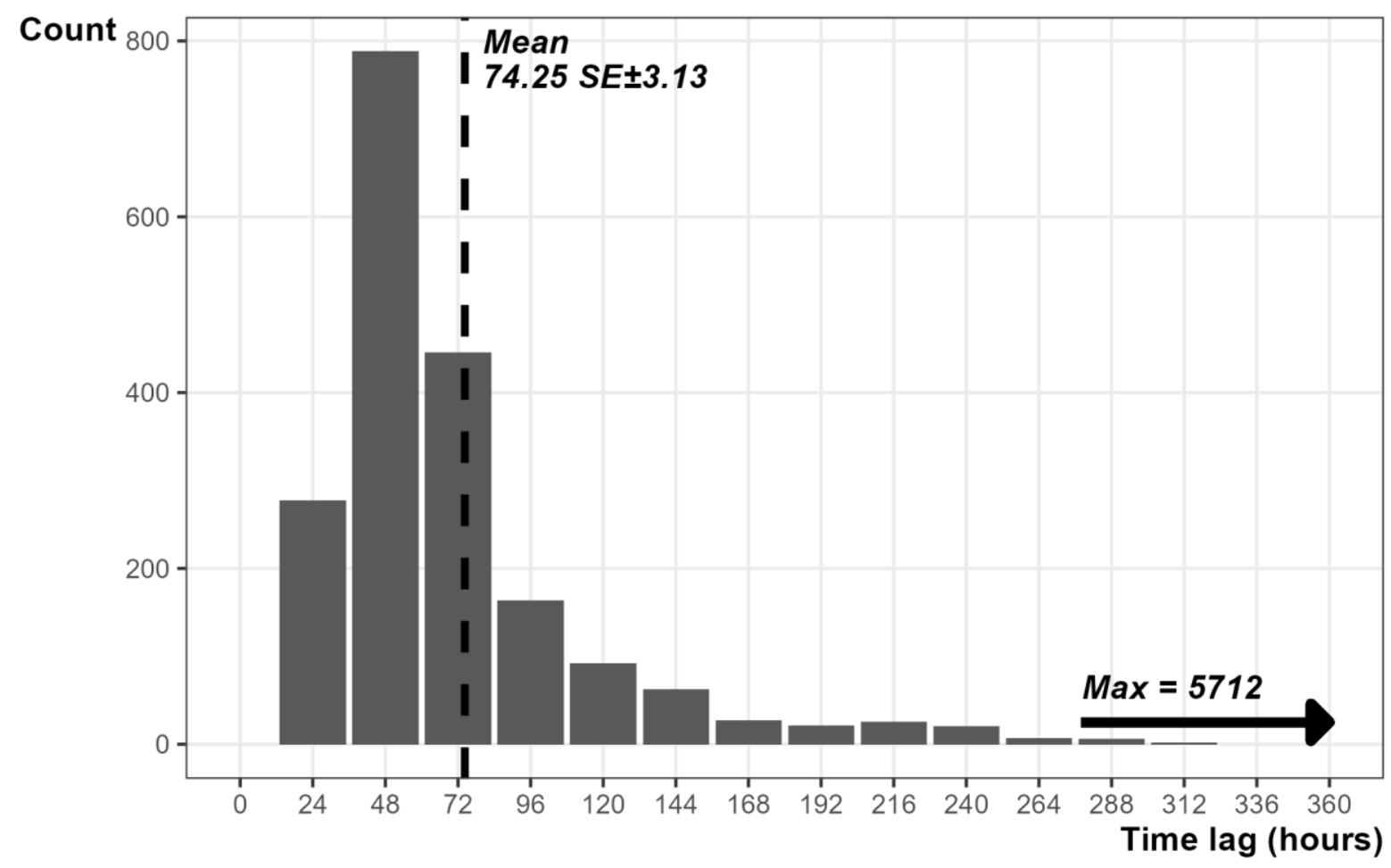

Figure S2 - Bar plot showing the time lag in hours between tracks, with mean (dashed line) annotated. 